\title{
Temperature conditions in the ventilation shaft lining and the space behind lining when reversing the main ventilation unit in winter
}

\author{
Aleksandr Kurilko ${ }^{1}$, Dmitrii Solovev ${ }^{* 1}$ \\ ${ }^{1}$ Chersky Institute of Mining of the North, Siberian Branch of the Russian Academy of \\ Sciences, 43, Lenina Avenue, Yakutsk, 677980, Russia
}

\begin{abstract}
Using mathematical modeling methods, the authors studied the temperature changes in the ventilation shaft lining and the space behind lining under an alternating thermal effect of the ventilation flow (reversing the main ventilation unit in winter). We established the pattern of the temperature conditions created in the ventilation shaft, the lining, and the host rock mass when reversing the main ventilation unit at mines in the North. Our studies have shown that, in case of emergency at the mine, which requires reversing the air flow in the coldest period of the year, it will result in a change in the temperature conditions in the ventilation shaft, the concrete lining, and the host rock mass. The extent of such effect depends on the reverse duration. Thus, at an ambient temperature of $-45^{\circ} \mathrm{C}$, during the first 24 hours after the reverse, we can observe complete freezing of the concrete lining at a ventilation flow rate of over $2 \mathrm{~m} / \mathrm{s}$. The rock temperature drops below $0^{\circ} \mathrm{C}$ and, at air flow rates of up to $10 \mathrm{~m} / \mathrm{s}$, the frozen area thickness around the shaft will be no more than $7 \mathrm{~cm} .48$ hours after the reverse, the maximum freezing depth of the rock will be $30 \mathrm{~cm}$.
\end{abstract}

Keywords: shaft, lining, temperature mode, ventilation, reverse.

\section{Introduction}

The operating temperature for mine shaft lining is one of the main factors determining its condition and the possibility of its long-term operation [1]. According tothe Federal Industrial Safety Standards and Regulations "Safety Rules for Mining and Processing of Solid Minerals" [2], air supplied to underground mine workings shall have a temperature of at least $+2^{\circ} \mathrm{C}$, which allows to prevent alternating temperature fluctuations and icing, thereby providing a safe and comfortable environment for mining.

It is known that the year-round temperature remains almost the same in the ventilation shafts, through which polluted air is released into the atmosphere. However, conditions with a sharp and significant change in the air flow temperature can be created in ventilation shafts; e.g., when reversing the air flow in winter (in case of emergency at the mine), when

*Corresponding authors: Solovjevde@igds.ysn.ru 
the shaft is used to supply air. In this case, the extent of effect of such change in the shaft air temperature on the lining condition depends on the time of using the shaft to supply air.

The most sensitive element to temperature fluctuations is the cast-iron tubing lining; a particularly adverse effect is caused by negative temperatures which can lead to a break in the bond between the cast iron tubing and the concrete coating, and rupture of connecting seams $[1,3]$. The impact of negative temperatures on cast-iron tubing lining when reversing the air flow in winter in the ventilation shaft has been studied in detail in the following publications: [4, 5]. Using Laplace transformations, the authors obtained integral dependencies which allow to calculate the air temperature in the shaft, to analyze changes in the temperature fields of the tubing column, the concrete coating, and the space behind lining.

At the diamond mines in Yakutia, the air temperature in ventilation shafts ranges from +2 to $+4{ }^{\circ} \mathrm{C}$ during the year. Heat flow penetrating deep into the rock mass creates an annular area of thawed rocks around the shaft.

When air with negative temperatures enters a ventilation shaft, it causes cooling and freezing of the lining and the thawed annular rock area around the vertical shaft. However, complete freezing of this area is unacceptable, since experience suggests that, to prevent deformation and destruction of the shaftconcrete lining with shear stresses occurring during the rock freezing in the space behind lining, there shall be a thawed annular damping area around the shaft. According some researchers $[6,7]$, the required minimum thickness of such area ranges from 0.5 to $1 \mathrm{~m}$.

\section{Theory}

Given the importance of the above issue, and based on the developed mathematical model [8], we studied the effect of reversing the main ventilation unit in winter on the temperature conditions in the lining and the space behind lining in a ventilation shaft for the conditions of diamond mines in Yakutia.

The calculations were made with the following initial parameters (that are typical for diamond mines in Yakutia): shaft diameter: $8 \mathrm{~m}$; concrete lining thickness: $0.5 \mathrm{~m}$; air temperature in the shaft: $+4{ }^{\circ} \mathrm{C}$; air flow rate: $200 \mathrm{~m}^{3} / \mathrm{s}$; natural temperature of the frozen rock enclosing the vertical shaft: $-3^{\circ} \mathrm{C}$; temperature of moisture phase transitions of the rock: $0^{\circ} \mathrm{C}$; density of concrete lining and rock mass, respectively: 2,500 and $2,300 \mathrm{~kg} / \mathrm{m}^{3}$; heat capacity of concrete lining and rock mass, respectively: 837 and $900 \mathrm{~J} /(\mathrm{kg} \cdot \mathrm{K})$; thermal conductivity of concrete lining: $1.505 \mathrm{~W} /(\mathrm{m} \cdot \mathrm{K})$; thermal conductivity of frozen and thawed rocks, respectively: 1.98 and $1.81 \mathrm{~W} /(\mathrm{m} \cdot \mathrm{K})$;rock mass moisture: 0.02 fraction units.

When calculating the temperature conditions in the shaft, the concrete lining, and the rock mass in the reverse ventilation mode, let us consider a case where the ambient air temperature drops to $-45^{\circ} \mathrm{C}$ at different ventilation flow rates in the shaft $(0.5 \mathrm{~m} / \mathrm{s}, 1 \mathrm{~m} / \mathrm{s}, 2$ $\mathrm{m} / \mathrm{s}, 5 \mathrm{~m} / \mathrm{s}$, and $10 \mathrm{~m} / \mathrm{s}$ ).

Figure 1 shows graphs of air temperature changes in the ventilation shaft at different air flow rates 24 hours after starting the reverse. As shown in the figure, with an increase in the air flow rate, the difference in air temperatures decreasesat the shaft mouth and at a depth of 200 meters. Thus, at an air flow rate of $0.5 \mathrm{~m} / \mathrm{s}$, this difference is $15^{\circ} \mathrm{C}$, whereas at a flow rate of $10 \mathrm{~m} / \mathrm{s}$, the difference decreases to about $3^{\circ} \mathrm{C}$. 


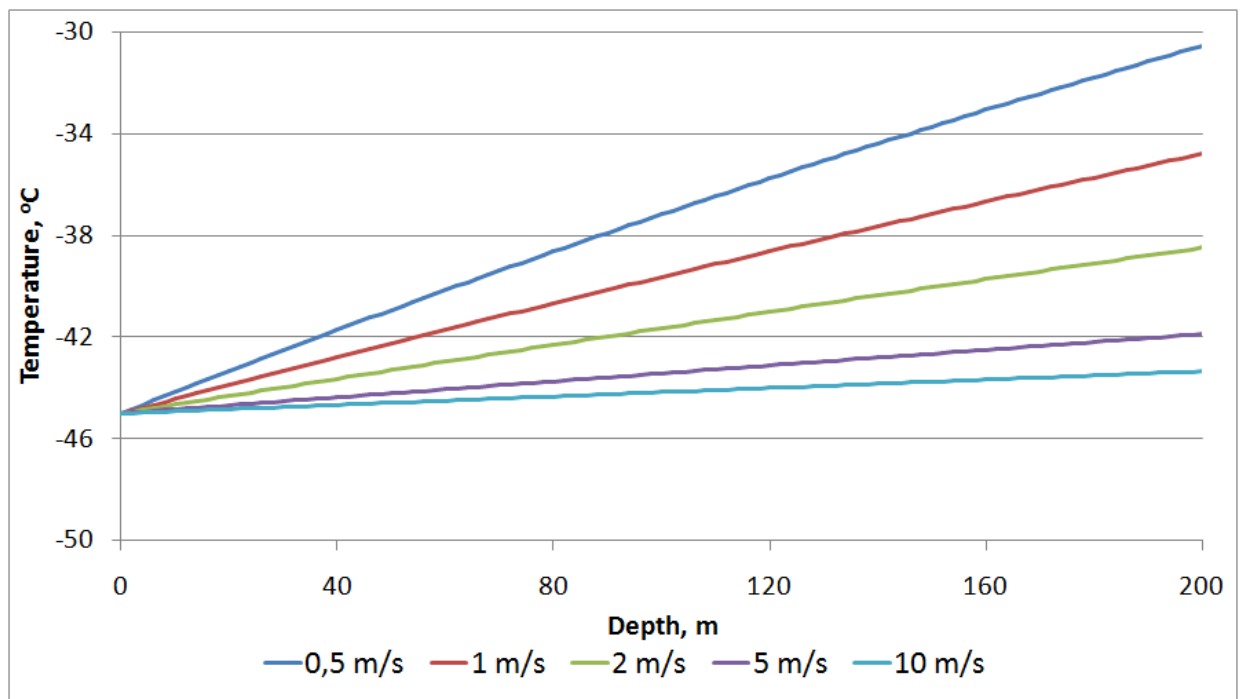

Fig.1. Air temperature distribution along the ventilation shaft depth in the reverse mode at different air flow rates (ambient temperature: $-45^{\circ} \mathrm{C}$ ).

Figure 2 shows the dynamics of changes in the air temperature along the shaft depth at different time intervals after starting the air stream reverse at a ventilation flow rate of 5 $\mathrm{m} / \mathrm{s}$. It is clearly seen that, during the first hours after the reverse, due to intense heat exchange between the air and the shaft lining, the difference in air temperatures at the shaft mouth and at a depth of 200 meters is about $10^{\circ} \mathrm{C}$; then, as the concrete lining freezes and the host rock temperature decreases, the heat exchange intensity decreases, and after 24 hours, this difference will be $3^{\circ} \mathrm{C}$.

Regardless of the air flow rate, we can see that the air temperature in the shaft is rather low. This will lead to ice formation on the lining, hardening of the shaft, and, accordingly, unsafe working conditions in the mine.

Figure 3 shows temperature distribution graphs along the ventilation shaft depth on the border of the lining and the rock at different time intervals at an air flow rate of $5 \mathrm{~m} / \mathrm{s}$. According to calculation results, the reverse of the air flowat the shaft mouth in the first few hours has virtually no effect on the temperature change at the contact between the lining and the rock. Only 18 hours after the reverse, the temperature in the above area drops to $0^{\circ} \mathrm{C} ; 24$ hours after, the temperature in the upper shaftat the contact between the lining and the rock will be below $-1^{\circ} \mathrm{C}$, and at a depth of $200 \mathrm{~m}$, it will be slightly higher: $-0.8^{\circ} \mathrm{C}$. 


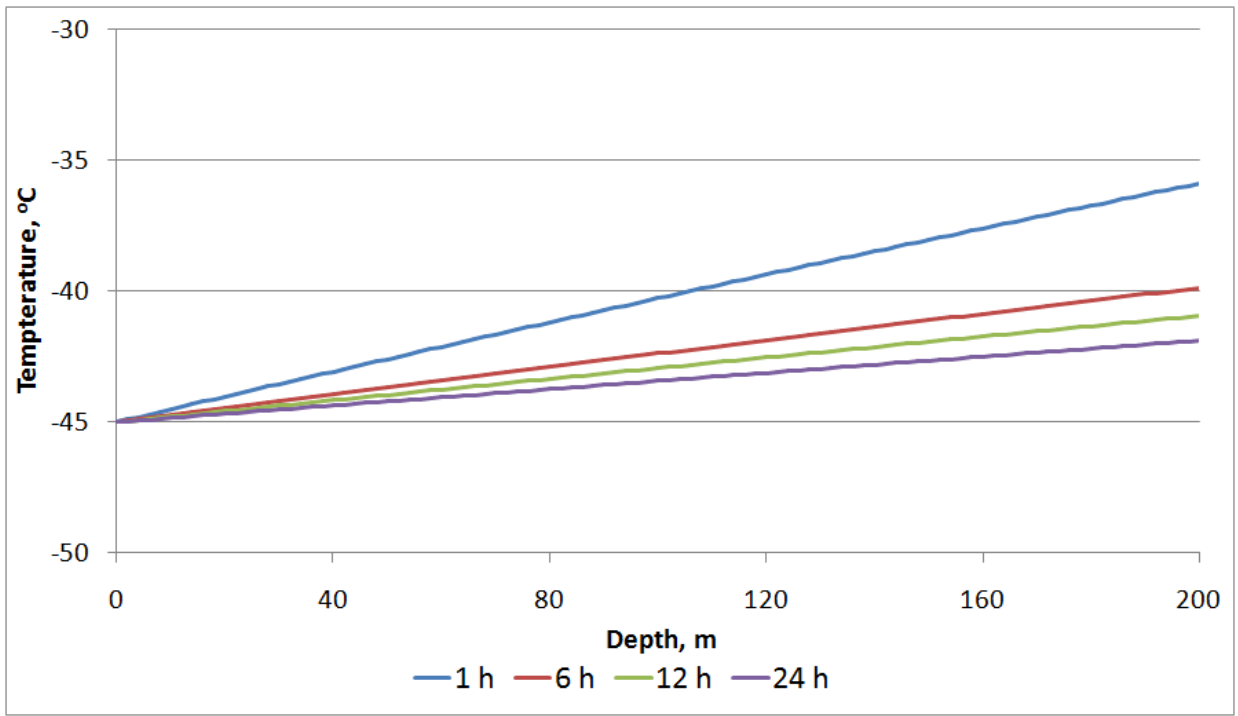

Fig.2. Air temperature distribution along the ventilation shaft depth at the air flow rate of $5 \mathrm{~m} / \mathrm{s}$ at different time intervals after starting the reverse (ambient temperature: $-45^{\circ} \mathrm{C}$ ).

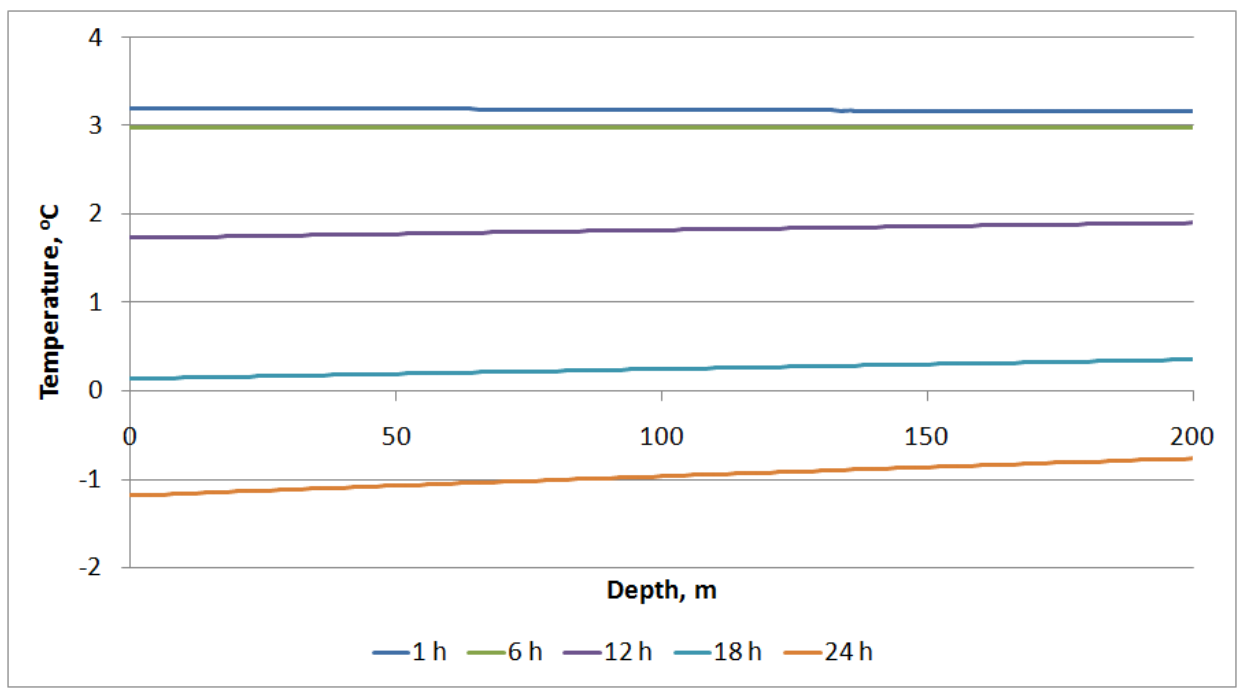

Fig.3. Air temperature distribution along the ventilation shaft depth at the contact between the lining and the rock at different time intervals and an air flow rate of $5 \mathrm{~m} / \mathrm{s}$ (ambient temperature: $-45^{\circ} \mathrm{C}$ ).

Figure 4 shows temperature graphs for the lining and the host rock at a depth of $50 \mathrm{~m} 24$ hours after starting the air flow reverse at different air flow rates in the shaft. As seen in the figure, the concrete lining is almost completely frozen in 24 hours. In addition, the rock temperature drops below $0^{\circ} \mathrm{C}$ to a shallow depth which, at flow rates of 2,5 , and $10 \mathrm{~m} / \mathrm{s}$, respectively, is 2,5 , and $7 \mathrm{~cm}$. Such insignificant rock area with negative temperatures cannot cause any adverse shear stress in the concrete lining.

Extending the reverse time up to 48 hours increases the rock area with negative temperatures, which in this case, at flow rates of 2,5 , and $10 \mathrm{~m} / \mathrm{s}$, will be 20,26 , and $30 \mathrm{~cm}$, respectively. However, at a flow rate of $1 \mathrm{~m} / \mathrm{s}$, the rock temperature also decreases; the thickness of this area is $14 \mathrm{~cm}$. A further increase in the air flow reverse time will only increase the rock area with negative temperatures in the space behind lining of the ventilation shaft, which can lead to frozen area heaving and the concrete lining destruction. 


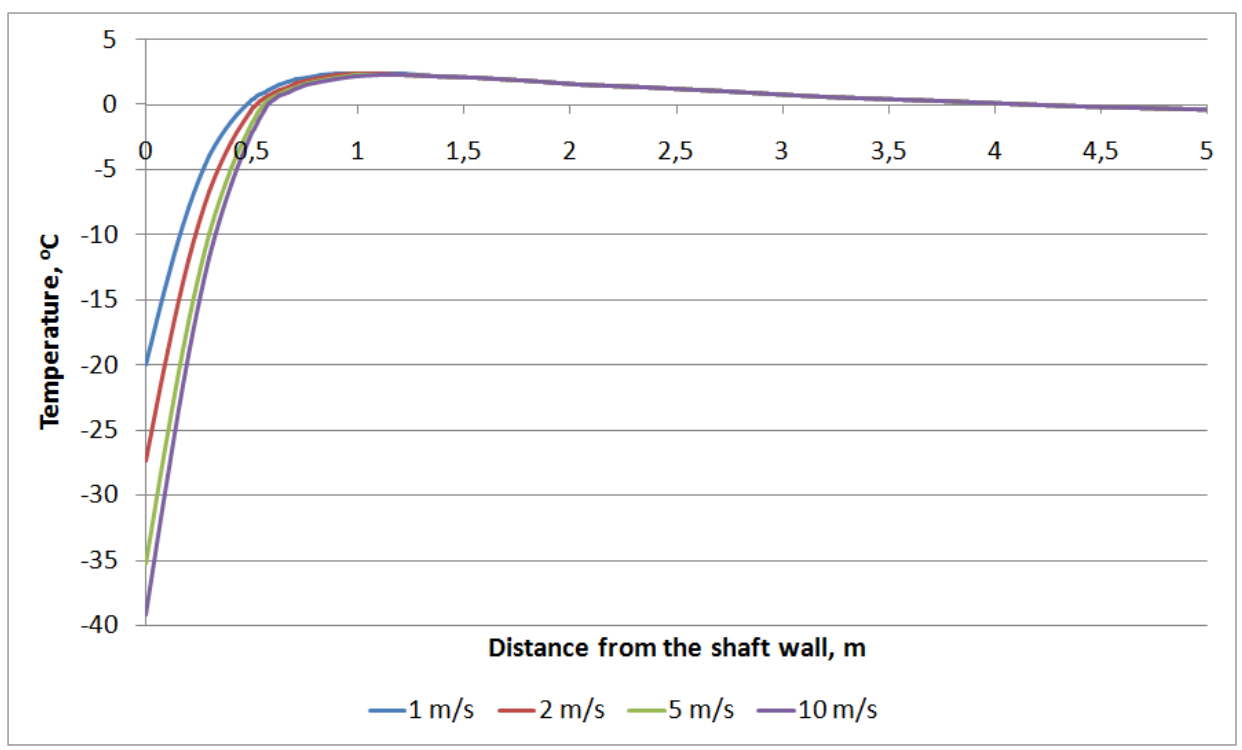

Fig.4. Temperature of the lining and the host rock at a dept of $50 \mathrm{~m} 24$ hours after the air flow reverse start (ambient temperature: $-45^{\circ} \mathrm{C}$ ).

It is known that the surface facilities of an underground mine with lifting through vertical shafts includes a bulky tower pile driver and pile fields around the shaft. This structure creates a huge load on the pile field, the stability of which is provided only at a certain soil temperature ensuring their permanent frozen state, which implies the mandatory artificial soil reinforcement in any way. The simplest and most effective way to strengthen thawing soils in permafrost conditions is their artificial freezing using freezing columns. At the same time, to prevent deformation and destruction of the shaft concrete lining by shear stresses occurring in the process of rock freezing in the space behind lining, there shall be a damping thawed annular area around the shaft, the required minimum thickness of such area ranging from 0.5 to $1 \mathrm{~m}$. The depth of this area at the shaft mouth is limited by the length of freezing columns and usually does not exceed $30 \mathrm{~m}$.

Figures 5 and 6 show temperature graphs for the lining and the rock mass enclosing the shaft at a depth of $20 \mathrm{~m}$ with the damping layer thickness of 0.5 and $1 \mathrm{~m}$, respectively, at various time intervals after starting the ventilation flow reverse and the air flow rate in the shaft equal to $5 \mathrm{~m} / \mathrm{s}$. As seen in the figures, a decrease in the rock temperature below $0^{\circ} \mathrm{C}$ in a $0.5 \mathrm{~m}$ thick damper layer occurs 48 hours after starting the reverse, and with a thickness of $1 \mathrm{~m}, 96$ hours after. At air flow rates in the shaft below $5 \mathrm{~m} / \mathrm{s}$, the damper layer freezing process increases. 


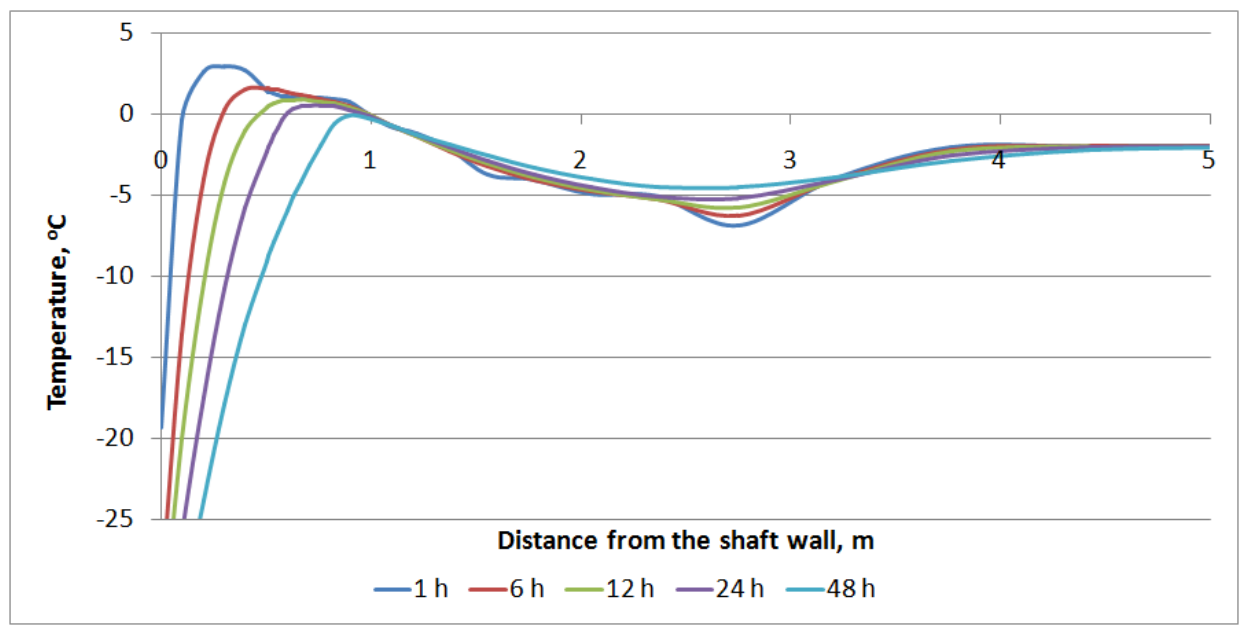

Fig.5. Temperature of the lining and the rock mass enclosing the shaft at a depth of $20 \mathrm{~m}$ with a damping layer thickness of $0.5 \mathrm{~m}$ at different time intervals after starting the ventilation flow reverse at the air flow rate in the shaft equal to $5 \mathrm{~m} / \mathrm{s}$ (ambient temperature: $-45^{\circ} \mathrm{C}$ ).

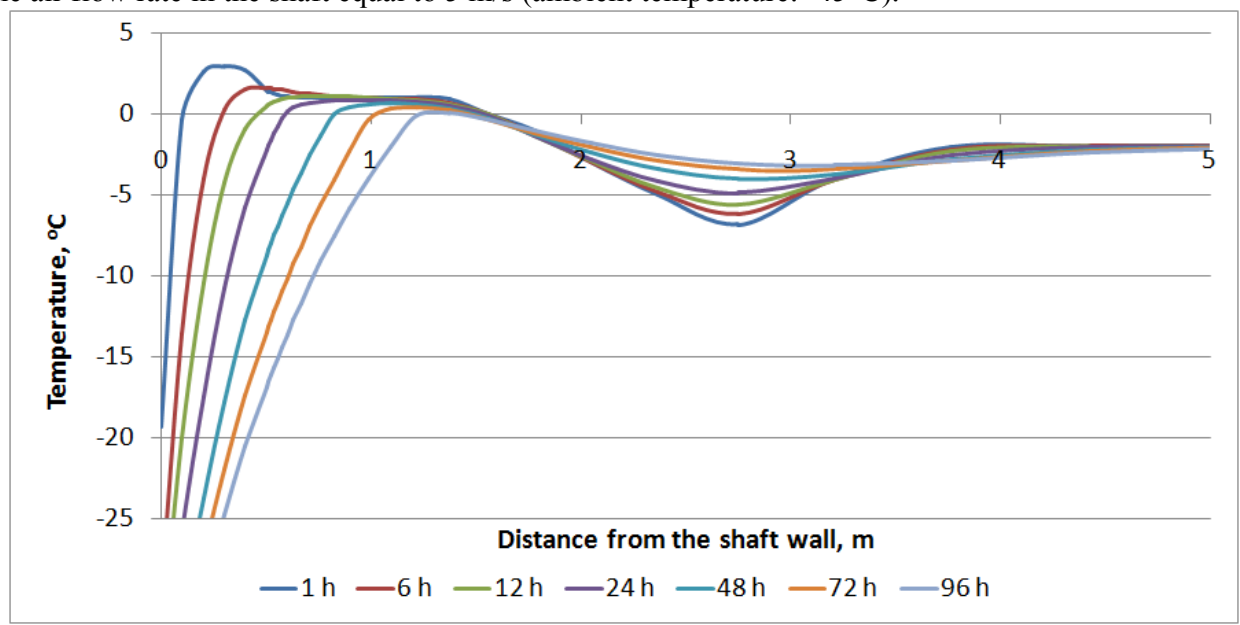

Fig.6. Temperature of the lining and the rock mass enclosing the shaft at a depth of $20 \mathrm{~m}$ with a damping layer thickness of $1 \mathrm{~m}$ at different time intervals after starting the ventilation flow reverse at the air flow rate in the shaft equal to $5 \mathrm{~m} / \mathrm{s}$ (ambient temperature: $-45^{\circ} \mathrm{C}$ ).

Therefore, reversing the air flow for a relatively long time leads to complete freezing of the rock mass between the lining and the frozen rock wall at the shaft mouth, which, in turn, can cause the concrete lining destruction.

\section{Conclusions}

Based on the developed mathematical model, we studied the reverse effect of the main ventilation unit in winter on the temperature conditions of the lining and the space behind lining of the ventilation shaft. The study shows that, in case of emergency at the mine which requires reversing the air flow in the coldest period of the year, it will result in the change of the temperature conditions in the ventilation shaft, the concrete lining, and the host rock mass. The extent of such effect depends on the reverse duration. Thus, at a temperature of $-45^{\circ} \mathrm{C}$ during the first 24 hours after the reverse, we can observe almost complete freezing of the concrete lining at ventilation flow rates of over $2 \mathrm{~m} / \mathrm{s}$. At the same time, the rock temperature at a shallow depth is below $0^{\circ} \mathrm{C}$, and, at air flow rates of 2,5 , 
and $10 \mathrm{~m} / \mathrm{s}$, it is 2,5 , and $7 \mathrm{~cm}$, respectively; where as 48 hours after the reverse, it is 20,26 , and $30 \mathrm{~cm}$, respectively. At the shaft mouth, the rock temperature drops below $0^{\circ} \mathrm{C}$ in the $0.5 \mathrm{~m}$ thick damper layer 48 hours after the reverse start, whereas with a thickness of $1 \mathrm{~m}$, 96 hours after (at the ventilation air flow rate in the shaft equal to $5 \mathrm{~m} / \mathrm{s}$ and the ambient temperature of $-45^{\circ} \mathrm{C}$ ).

\section{Bibliography}

1. Yu.P. Olkhovikov Lining for Permanent Workings at Potash and Salt Mines. (Moscow: Nedra, 1984)

2. $\quad$ Federal Industrial Safety Standards and Regulations "Safety Rules for Mining and Processing of Solid Minerals" (2014)

3. N.G. Trupak Methods to Prevent Water Ingress in Potash and Salt Mines When Sinking Shafts (Moscow: Gosgortekhizdat, 1961)

4. $\quad$ B.P. Kazakov, A.V. Shalimov, Industrial Labor Safety, 10 (2006)

5. B.P. Kazakov, A.V. Shalimov, E.L. Grishin, Physical and Engineering Problems of Mining, 5, 92-98 (2011)

6. N.P. Kramskov, Science and Education, 1 (2004)

7. V.I. Sleptsov, S.D. Mordovskoy, V.Yu. Izakson Mathematical Modeling of Heat Exchange Processes in Permafrost Rocks (Novosibirsk: Nauka. Siberian Publishing Company of the RAS, 1996)

8. Yu.A. Khokholov, A.S. Kurilko, D.E. Solovev, Physical and Engineering Problems of Mining, 3, 176-184 (2016) 